\title{
A VITÓRIA DO ANIMAL LABORANS E O GIRO DA MÁQUINA ANTROPOLÓGICA
}

\author{
The victory of the animal laborans and the spin of the anthropological machine
}

\author{
Daniel Arruda Nascimento ${ }^{1}$ \\ Edson Kretle dos Santos ${ }^{2}$
}

\section{RESUMO:}

Pretendemos nessas breves reflexões conjuntas explorar a harmonia crítica que se estabelece entre Hannah Arendt e Giorgio Agamben, mormente em relação às idiossincrasias do homem qualificado como animal laborans e da máquina antropológica, com a finalidade maior de expor algumas associações entre animalização e despolitização. Por um lado, temos a percepção de que o homem moderno reduziu a vida comum a uma única dimensão da existência, a ocupação com o processo metabólico e a labuta para a manutenção dessa mesma existência, tornando a política agora capturada por essa priorização, abandonando-a ao fim. Entre o labor do consumo, o trabalho da fabricação e a ação da política, perdeu essa última definitivamente o seu espaço original. Em uma curiosa aproximação entre o animal e o consumidor, a vida vitoriosa do animal laborans, presa na dinâmica do consumo desenraizado, será então a única que interessará ao homem moderno. Por outro lado, uma furiosa máquina antropológica que atravessa os tempos cospe produtos em dois sentidos: humaniza o animal e animaliza o ser humano, isolando-o em uma vida nua. Se a vida biológica se torna uma tarefa política no horizonte da biopolítica, a vida nua ainda que não seja necessariamente animal será a insígnia de uma vida tornada novamente animal. Tanto o animal laborans quanto o resultado da máquina antropológica na sua versão moderna são entes que perderam a sua vocação política, são seres antipolíticos, esvaziados de ação, de discurso, de direitos, de capacidade de compreensão.

Palavras-chave: Animal laborans; máquina antropológica, despolitização.

\begin{abstract}
:
In these brief joint reflections, we intend to explore the critical harmony that is established between Hannah Arendt and Giorgio Agamben, especially in relation to the idiosyncrasies of man qualified as animal laborans and of the anthropological machine, with the main purpose of exposing some associations between animalization and depoliticization. On the one hand, we have the perception that modern man has reduced ordinary life to a single dimension of existence, the occupation with the metabolic process and the struggle to maintain that same existence, making politics now captured by this prioritization, abandoning it at last. Between the work of consumption, the work of manufacturing and the action of politics, the latter definitively lost its original space. In a curious approximation between the animal and the consumer, the victorious life of the animal laborans, trapped in the dynamics of uprooted consumption, will then be the only one that will interest modern man. On the other hand, a furious anthropological machine that crosses time spits out products in two directions: it humanizes the animal and animalizes the human being, isolating it in a bare life. If biological life becomes a political task on the horizon of biopolitics, the bare life, even though it is not necessarily animal, will be the insignia of a life made animal again. Both the animal laborans and the result of the anthropological machine in its modern version are entities that have lost their political vocation, they are anti-political beings, emptied of action, speech, rights, capacity for understanding.
\end{abstract}

\footnotetext{
${ }^{1}$ Doutor em Filosofia pela Universidade Estadual de Campinas. Professor Associado do Instituto de Ciências da Sociedade da Universidade Federal Fluminense. Professor permanente do Programa de Pós-Graduação em Filosofia da Universidade Federal do Espírito Santo. E-mail: danielarrudanascimento@id.uff.br.

2 Doutorando pelo Programa de Pós-Graduação em Filosofia da Universidade Federal do Espírito Santo. Professor do Instituto Federal de Educação, Ciência e Tecnologia do Espírito Santo. E-mail: edsonkretle@gmail.com.
} 
Keywords: Animal laborans; anthropological machine, depoliticization.

\section{Introdução}

Pretendemos nessas breves reflexões conjuntas explorar a harmonia crítica que se estabelece entre Hannah Arendt e Giorgio Agamben, mormente em relação às idiossincrasias do homem qualificado como animal laborans e da máquina antropogênica, ou antropológica, com a finalidade maior de expor algumas associações entre animalização e despolitização. Por um lado, temos a percepção de que o homem moderno reduziu a vida comum a uma única dimensão da existência, a ocupação com o processo metabólico e a labuta para a manutenção dessa mesma existência, tornando a política agora capturada por essa priorização, abandonando-a ao fim. Entre o labor do consumo, o trabalho da fabricação e a ação da política, perdeu essa última definitivamente o seu espaço original. Em uma curiosa aproximação entre o animal e o consumidor, a vida vitoriosa do animal laborans, presa na dinâmica do consumo desenraizado, será então a única que interessará ao homem moderno. Por outro lado, uma furiosa máquina antropológica que atravessa os tempos cospe produtos em dois sentidos: humaniza o animal e animaliza o ser humano, isolando-o em uma vida nua. Se a vida biológica se torna uma tarefa política no horizonte da biopolítica, a vida nua ainda que não seja necessariamente animal será a insígnia de uma vida tornada novamente animal. Tanto o animal laborans quanto o resultado da máquina antropológica na sua versão moderna são entes que perderam a sua vocação política, são seres antipolíticos, esvaziados de ação, de discurso, de direitos, de capacidade de compreensão.

Os gregos ensinaram sobre a importância de propósitos para tornar possível a existência humana. A herança desse modo de pensar pode ser detectada na clássica frase de Sócrates: uma vida sem busca não é digna de ser vivida (cf. REALE; ANTISERI, 2005, p. 05). Viver com projetos, objetivos e metas pessoais ou coletivas concede forças para enfrentar os desafios do cotidiano. Se há o risco de se viver permanentemente no futuro incerto, há aí também uma fonte de motivação e energias para o dia em que se vive. No entanto, o problema de uma época calcada no desempenho surge quando as cobranças externas e aquelas que fazemos em nós mesmos se transformam em angústia, ansiedade, paralisia e a vida se torna apenas questão de sobrevivência. Desde muito pequenos somos confrontados com demandas pequenas e grandes, algumas inatingíveis. E na sociedade do consumo onde somos inseridos com uma profundidade cada vez maior, as necessidades se tornam cada vez menos necessárias. Os desafios impostos por esse cenário e por esse modo de agir que se torna comportamental nos remetem a repetir a mesma provocação de Hannah Arendt e parar mais uma vez para "pensar o que estamos fazendo" (ARENDT, 2016, p. 06).

Se os últimos séculos viram a insurgência da sociedade disciplinar e de controle, hoje nós somos a sociedade do desempenho. Com a consciência dragada por tantas outras coisas que não nós mesmos ou tornados empreendedores de nós mesmos em permanente surto egocêntrico, 
usamos todos os recursos disponíveis para majorar o nosso desempenho e vivemos sempre cansados, exaustos porque nossa mente não desliga nenhum minuto. Com a cabeça a vaguear pelas preocupações com o trabalho, o prestígio, o dinheiro, os projetos, a pressão por desempenho é tão grande que nos finais de semana, feriados ou até mesmo nas férias, nos sentimos culpados por sermos improdutivos, sendo ao mesmo tempo vítimas e agressores de nós mesmos. Fomos ensinados a pensar que a vida útil é apenas aquela que levamos quando estamos em intensa atividade, sempre ocupados com alguma coisa que ainda não fizemos. Talvez como uma forma de fugirmos daquilo que não temos coragem de admitir: não somos super-homens. Não é certamente sem razões que somos o século da depressão: doenças como a depressão, o transtorno de déficit de atenção com hiperatividade, o transtorno de personalidade limítrofe ou a síndrome de burnout são diagnósticos comuns nos consultórios apinhados de gente. Tendo a vida se tornado um sobreviver, “o cansaço da sociedade do desempenho é um cansaço solitário, que atua individualizando e isolando" (HAN, 2015, p. 71)3. A preocupação constante com o desempenho não apenas nos adoece, mas mingua a possibilidade da política. O cuidado com a vida substituiu toda ação política. O animal laborans é um homem depressivo (cf. HAN, 20015, p. 28).

Arendt e Agamben são autores relevantes para a compreensão das peculiaridades políticas que marcam o mundo contemporâneo, caracterizado como uma época despolitizada, de conformismo e apatia política. Em ambos, encontramos os elementos que levaram "a vida biológica como tal, ocupar progressivamente o centro da cena política do moderno" (AGAMBEN, 2002, p. 11). No último capítulo de $A$ condição humana, a pensadora alemã descreve o processo de alienação do mundo que atinge seu ponto mais alto na vitória do animal laborans na era moderna - e não deixa de ser curioso que a expressão ai escolhida seja animal e não homo, a enfatizar o fato de dividirmos com os animais as funções vitais. Esse novo estado do homem pode ter sido decisivo para tudo o que viria posteriormente. Em Origens do totalitarismo, ela explica que através da propaganda e da redução da capacidade de pensar, os regimes totalitários inventaram uma verdade oficial ancorada numa ideologia, potencializada na atomização dos indivíduos e na distribuição da violência e do terror. Os horrores da experiência da concentração aniquilaram milhões de pessoas e garantiram o terrível e aberrante fato de que, sob determinações cientificamente rigorosas e planejadas, é possível destruir a espontaneidade humana. De modo que "o totalitarismo e a bomba atômica - suscitam a pergunta sobre o significado da política em nossa época. Trata-se de experiências fundamentais de nossa época. Ignorá-las é como nunca ter vivido no mundo que é o nosso mundo" (ARENDT, 2009, p. 163). Extinguindo a individualidade e a espontaneidade dos sujeitos, transformando as pessoas em coisas, objetiva-se abater o adversário a fim de torná-lo incapaz de toda e qualquer resistência. Mais tarde, em Eichmann em Jerusalém: um relato sobre a banalidade do mal, a pensadora alemã infere que "talvez a natureza de toda burocracia, seja transformar homens em funcionários e meras

\footnotetext{
3 Na edição ampliada de 2017 do livro do filósofo sul-coreano Byung-Chul Han, encontramos em suas últimas páginas anexas a seguinte frase: “a vida de hoje se transformou em um sobreviver” (p. 117).
} 
engrenagens, assim os desumanizando" (ARENDT, 1999, pp. 312-313). Podemos transformar sujeitos de direitos em menos que animais ou um simples feixes de reações que, dadas as mesmas condições, sempre reagirão de modo análogo (cf. ARENDT, 2008).

Reconhecendo a sua influência, assumindo como premissa que a politização do biológico faz da vida o bem supremo e fundamento da vida hodierna, bem como o advento da biopolítica, o filósofo italiano estará em Homo sacer: o poder soberano e a vida nua em condições de afirmar que "o ingresso da zoé na esfera da pólis, a politização da vida nua como tal constitui o evento decisivo da modernidade" (AGAMBEN, 2002, p. 12). Considerando-se que entre os gregos o termo bios designava a maneira própria de viver de um indivíduo ou de um grupo e que o termo zoé indicava o simples fato de viver, a vida natural, o que é comum a todos os seres viventes, humanos e animais, "se algo caracteriza a democracia moderna em relação à clássica, é que ela se apresenta desde o início como uma reivindicação e uma liberação da zoé, que ela procura constantemente transformar a mesma vida nua em forma de vida e de encontrar, por assim dizer, o bios da zoê" (AGAMBEN, 2002, p. 17), ou seja, uma maneira própria de viver da vida considerada apenas em seu aspecto biológico natural. Vida natural, cumpre acrescentar, que uma vez exposta aos poderes soberanos e à gestão de vida e de morte, restará vida nua. Os eventos totalitários do século vinte foram materializados apenas porque antes o campo havia se tornado o espaço próprio da política, como um desmembramento terrível, mas coerente. "Somente porque no nosso tempo a política se tornou integralmente biopolítica, ela pode constituir-se em uma proporção antes desconhecida como política totalitária" (AGAMBEN, 2002, p. 126). Com a publicação de $O$ aberto: o homem e o animal, tendo mais uma vez como pano de fundo a tese de que a política é cooriginariamente biopolítica, o filósofo italiano procurará demonstrar como, as ciências organizam a compreensão pública acerca do que é o ser humano, orientando diferentes domínios no qual a distinção entre homem e animal não mais é evidente. "O conflito político decisivo, que governa todo e qualquer outro conflito, é, em nossa cultura, aquele entre a animalidade e a humanidade do homem" (AGAMBEN, 2013, p. 130).

Nas linhas que se seguem, teremos o primeiro momento centrado na abordagem da compreensão arendtiana sobre a vitória do animal laborans, contando com processos da era moderna que afetaram diretamente as sociedades políticas, a substituição do cidadão pelo consumidor, a noção de liberdade burguesa e a confusão entre os espaços público e privado, para em um segundo momento colocarmos em relevo o funcionamento da máquina antropológica agambeniana, o gerenciamento científico e estatal da vida biológica, a politização que resulta em animalização, a animalização que resulta em despolitização da vida humana. Temos a lucidez de que a política habita o cenário da contingência, sempre existirá a possibilidade de surgirem formas de governo que transformem a vida humana em algo tão politizado que elimine a liberdade de ação dos sujeitos. Ou que a politização da vida implique mesmo na despolitização dos sujeitos. Tal fato amedronta porque somos uma geração sem garantias diante do fracasso do Estado Democrático de Direito. 
Poderia a vitória do animal laborans nos conduzir ao fim das democracias liberais? Poderia a vida nua expelida da maquina antropológica ser o paradigma de uma espécie de zoologia política sem retorno? As provocações e os alertas de Arendt e Agamben sugerem o conhecimento de que já não existe nenhum mecanismo político ou jurídico que assegure que os atuais e defendidos regimes democráticos não se transformem nos estados totalitários. Os acontecimentos do nosso tempo exigem a necessidade de uma filosofia política que se posicione e interprete os riscos iminentes do retorno à barbárie.

\section{A vida como bem supremo: a vitória do animal laborans}

Embora seja comum encontrar entre os comentadores de Hannah Arendt a conclusão de que o capítulo sobre a ação seja o coração de $A$ condição humana, o capítulo da vitória do animal laborans é conclusivo. Nele, a pensadora política alemã descreve três eventos que definiram os rumos do mundo contemporâneo e o processo de alienação: a chegada dos europeus ao continente americano, a reforma protestante e a invenção do telescópio. A descoberta do novo mundo possibilitou que toda a Terra fosse explorada, proporcionou uma maior velocidade nos meios de locomoção e comunicação, tornando o globo terrestre pequeno. Por sua vez, a reforma protestante, ao expropriar os bens das instituições eclesiásticas tradicionais, gerou um intenso acúmulo de riqueza e o surgimento de uma economia capitalista cujo "processo de riqueza, tal como o conhecemos, estimulado pelo processo vital e, por sua vez, estimulando a vida humana, é possível somente se o mundo e a própria mundanidade do homem forem sacrificados" (ARENDT, 2016, p. 317). Esses acontecimentos resultaram no processo de alienação em relação ao mundo, assim como no declínio do Estado-nação, visto que "a inadequação do Estado-nação à vida do mundo moderno já foi há tempos demostrada, e quanto mais as pessoas se apegarem a ele, mais cruéis e temerários serão as formas através das quais o Estado-nação e o nacionalismo, tendo sido pervertidos, se fortalecerão" (ARENDT, 2021, p. 305). Conforme atesta um contemporâneo nosso, "a ideia da nação como instância soberana e constituidora da legalidade, da gestão e organização política que propiciou o surgimento na contemporaneidade dos seres sem estados, sem direito, sem sociedade: os apátridas e os refugiados” (AGUIAR, 2017, p. 87). No século dezessete, Galileu Galilei descobre vários fenômenos celestes e fornece evidências ao heliocentrismo copernicano pelo uso do telescópio. Com o surgimento da explicação dos fenômenos da natureza, notando-se como método científico que o livro da natureza está escrito em caracteres matemáticos, o astrônomo florentino contribui para que as investigações dos cientistas sejam acareadas com a experiência. O mundo passa a ser interpretado por uma linguagem técnica, científica e limitada pelo vocabulário da matemática e dos especialistas. Onde "a uniformidade estatística não é de modo algum um ideal científico inócuo; é sim o ideal político, não mais secreto, de uma sociedade que, inteiramente submersa na rotina da vida cotidiana, aceita pacificamente a concepção científica inerente à sua própria existência" (ARENDT, 2016, p. 53). Como consequência, o surgimento das ciências naturais e o grande 
aumento do conhecimento humano foram acompanhados pelo crescimento do niilismo e desespero onde o homem "ao invés de encontrar a natureza do universo, encontra apenas a si mesmo" (ARENDT, 2016, p. 324).

Alicerçadas na ilusão do progresso, as ciências produziram um ser humano que age em conformidade com os interesses, padrões e previsões comportamentais que convém ao Estado. "Experimentos econômicos, sociais, e psicossociais, em geral, são ensaiados e reproduzidos in vivo (e não in vitro) pelos engenheiros da sociedade" (ALMEIDA, 2020, p. 56). Toda a política contemporânea é precedida por uma espécie de antropologia que funda e orienta o convívio. Subjaz na visão de homem o desejo moderno de controlar, adestrar a natureza humana e eliminar qualquer comportamento que gere imprevisibilidade aos padrões ditados pelos poderes soberanos. "O estabelecimento do Commonwealth, a criação humana de 'um homem artificial', equivale à construção de um 'autômato [uma máquina] que [se] move por meio de molas e rodas, como um relógio"” (ARENDT, 2016, p. 371). Na modernidade, a introspecção gerada pela dúvida cartesiana e as transformações científicas e tecnológicas conduziram a conquista do homo faber sobre a contemplação dos medievais, gerando uma nova mentalidade que sustenta que o homem conhece apenas aquilo que ele próprio faz. A partir de então, desse novo modo de conceber a realidade e da perda das tradições e do mundo comum, "nem Deus nem um espírito mau podem alterar o fato de que dois mais dois são quatro" (ARENDT, 2016, p. 353). Se a humanidade possui agora tão grande poder de criar e produzir a sua realidade, os homens individuais se encontram presos aos padrões que seus utensílios mesmo forjaram - temos aí o triunfo da produtividade, da ideia de desenvolvimento, da razão instrumental e a oniabrangência da relação entre meios e fins. $O$ domínio do homo faber que se realiza no trabalho e "é por causa da conexão que todas as atividades do trabalho têm com as necessidades estritamente biológicas de nosso corpo que ele tradicionalmente foi relegado a integrar as funções menos elevadas e quase animalescas da vida humana, e, como tal, considerado uma questão do mundo privado" (ARENDT, 2021, p. 46). Com o desenrolo do processo de alienação do mundo e da máxima da maior felicidade ao maior número dos séculos dezoito e dezenove, entretanto, fomos conduzidos à vitória do princípio da própria vida sobre o homem da fabricação.

[...] Estamos lidando com uma filosofia de vida em sua forma mais vulgar e menos crítica. Em última análise, a vida mesma é o critério supremo ao qual tudo mais se reporta, e os interesses do indivíduo, bem como os interesses da humanidade, são sempre equacionados com a vida individual ou a vida da espécie, como se fosse óbvio que a vida é o bem supremo (ARENDT, 2016, p. 387).

Nas últimas páginas de $A$ condição bumana, a pensadora alemã procura investigar as razões que levam o bomo faber a ceder espaço ao animal laborans. Mesmo todo o processo de secularização desencadeado pela modernidade foi incapaz de fragilizar a estrutura produzida pelo conceito de vida da tradição cristã: "a sacralidade da vida sobrevivera à secularização e ao declínio geral da fé 
cristã, que nem mesmo chegaram a abalá-la" (ARENDT, 2016, p. 389). Não há aqui nada de inofensivo: novas configurações de mundo trazem sérias consequências políticas para as sociedades contemporâneas. A promessa da imortalidade individual proclamada pela mensagem cristã, tendo a morte enquanto fim da vida neste mundo e início de um novo ciclo de vida em outro mundo, especialmente nos escritos paulinos, teria invertido os alicerces das relações sociais. De acordo com a autora, "a 'boa nova' cristã da imortalidade da vida humana individual invertera a antiga relação entre o homem e o mundo, promovendo aquilo que era mais mortal, a vida humana, à posição de imortalidade ocupada até então pelo cosmo" (ARENDT, 2016, pp. 389-390). O homem político arrefece. Com isso, as palavras e os feitos não serão mais o centro da imortalidade mundana a engendrar a ação política. "Foi precisamente a vida individual que passou então a ocupar a posição antes ocupada pela 'vida' do corpo político" (ARENDT, 2016, p. 390). Esse processo de secularização impulsionou a vitória do animal laborans: "a única coisa que poderia ser potencialmente imortal, tão imortal quanto fora o corpo político na Antiguidade ou a vida individual na Idade Média, era a própria vida, isto é, o processo vital possivelmente eterno da espécie humana" (ARENDT, 2016, p. 398).

Por conseguinte, a vida política teria sido sucedida pelos desejos e pelas disposições da vida individual. O homem moderno se torna um ser incapaz de pensar e agir em conjunto, uma vez que o animal laborans é inábil para habitar o domínio público. "O homem isolado que perdeu o seu lugar no terreno político da ação é também abandonado pelo mundo das coisas, quando já não é reconhecido como homo faber, mas tratado como animal laborans cujo necessário 'metabolismo com a natureza' não é do interesse de ninguém. É aí que o isolamento se torna solidão" (ARENDT, 1989, p. 527). A sociedade de trabalhadores e consumidores vive apenas para prover o próprio sustento e anseia pela riqueza e abundância oriunda do cálculo da prosperidade. O animal laborans admitido no mundo público é desqualificado para as atividades que não sejam apenas de cunho privado. A sociedade de massas presencia o aumento do isolamento onde os vínculos são destruídos e a convivência se torna difícil, a vida contemporânea transforma-se em vida árida pela impossibilidade de comunicação e contato entre mulheres e homens. Isolados uns dos outros, apenas encontram tempo para produzir e consumir. Com a sua insatisfação e infelicidade permanente, "o tempo excedente do animal laborans jamais é empregado em algo que não seja o consumo, e quanto maior é o tempo de que ele dispõe, mais ávidos e ardentes são os seus apetites” (ARENDT, 2016, p. 165). No último estágio contemporâneo, apesar das milhares de conexões possíveis da era digital, o animal laborans se torna um sujeito fechado em si mesmo. Vazios de amizade cívica e repletos de antipatia social ergue-se o risco de que nenhum objeto do mundo, e igualmente, nenhuma instituição política social estejam salvos do culto à riqueza e de serem consumidas pelo consumismo. E “o perigo é que tal sociedade, deslumbrada pela abundância de sua crescente fertilidade e presa ao suave funcionamento de um processo interminável, já não seria capaz de reconhecer a sua própria futilidade - a futilidade da vida" (ARENDT, 2016, p. 167). 
Uma sociedade de consumidores é indiferente e até hostil às questões públicas, frequentemente apresenta um comportamento coletivo propenso para o surgimento de regimes totalitários. A vitória animal laborans cria um comportamento existencial centrado na especificidade do simples estar vivo (cf. CORREIA, 2013, p. 218). Teremos então um modo de vida intimamente relacionado com o metabolismo ininterrupto do labor e do consumo, com resultados altamente danosos às relações sociais, econômicas e políticas, visto que não mais existe espaço para a singularidade e diferenciação entre os indivíduos. A autonomia do pensamento e a cidadania se tornam experiências difíceis, pois o comportamento do animal laborans se reduz a movimentos orientados por cálculos do incessante processo vital. A vitória do animal laborans é a vitória dos consumidores contra os cidadãos e contra os eleitores. Isto é dizer que os eleitores se comportam como consumidores, a política mudou. Assim como é costume compensar as frustrações cotidianas com a vida abusando do consumo de comidas e bebidas, a frustração com a política se traduz no consumo indiscriminado de imagens e notícias.

Nossa contemporaneidade compreende um processo homogeneização que conduz os indivíduos a agirem da mesma forma diante de estímulos ritmados, o que se torna ainda mais evidente na exposição de um tipo de governamentalidade que é agora guiada por algoritmos. Embora pareça que somos nós a manipular sistemas de informação e os benefícios das redes sociais, somos nós os manipulados, somos nós os que sofremos os seus apelos e determinações. Embora vendam a si mesmas como espaços de crescimento, as redes sociais forjam subjetividades e comportamentos: as mensagens que recebemos diariamente, inclusive de familiares em quem confiamos, influenciam pensamentos e comportamentos de modo inaudito. Embora vendam a si mesmas como espaços de democracia, as redes sociais enfraquecem e impacientam o debate público, tornando-os espaços férteis para o ódio e a violência ${ }^{4}$. Consequentemente, um mundo cada vez mais carente de ideias, o que seria essencial para a democracia, tem como companhia o assalto contra as instituições públicas e a estabilidade dos corpos políticos contemporâneos. A lógica algorítmica produz e reproduz subjetividades despolitizadas. Informações, relacionamentos, desejos e condutas de sujeitos capturados pelos apartados digitais são classificados e organizados em ambientes que se assemelham a bolhas discursivas, ideológicas e identitárias, a perfis alimentados

\footnotetext{
${ }^{4}$ Dois documentários recentes, aqui recomendados, pautam o debate com fluidez e linguagem acessível: The Great Hack (2019) e The Social Dilema (2020). As esquerdas no país já se deram conta de que a política não é mais a mesma, especialmente após o impacto do uso de algoritmos nas eleições presidenciais nos Estados Unidos da América em 2016 e nas eleições presidenciais no Brasil em 2018, mas demonstram que ainda não sabem como reagir. A pandemia que assolou o globo terrestre em 2020, aprofundando e agravando a nossa dependência aos computadores de todo tipo e aos meios digitais, parece ter gerado consequências permanentes no mundo político e humano. Na ressaca das eleições municipais de 2020, a presidenta do principal partido a reivindicar a liderança do espectro político de esquerda no país publica um texto bem articulado que, se tem a vantagem de estabelecer um contraponto ao discurso hegemônico imposto pela grande mídia, tem a desvantagem de parecer completamente anacrônico diante do cenário atual (Cf. Gleisi: um balanço político das eleições. Disponível em https://pt.org.br/gleisi-um-balanco-politico-das-eleicoes/. Acesso em 07/12/2020).
} 
automaticamente, impondo novos limites à liberdade política e à cidadania nas sociedades contemporâneas.

\footnotetext{
Seus mecanismos suscitam desejos e necessidades de consumo e de posições políticas e ideológicas, despolitizam mediante a anulação das subjetividades políticas, diminuindo as esferas do debate, das escolhas, da diversidade. [...] Ocorre um definhamento, quando não a eliminação direta, das deliberações políticas e das reflexões plurais e diversificadas. O saber que emerge aparece como verdade real, imparcial e indubitável dos traços deixados pelos indivíduos. A divergência política, o dissenso coletivo, as resistências e contestações sofrem a invisibilidade e a inoperosidade (TELES, 2018, pp. 446-447).
}

O tema da vitória do animal laborans pode ser relacionado com o aparecimento de uma racionalidade conduzida pelos algoritmos e despolitizada. Se é evidente que em sua época os problemas típicos da era digital não estavam no radar de Arendt, também é certo que o tipo de comportamento caracterizado pela perda das experiências existenciais, discursivas e afetivas propriamente políticas, "requer de seus membros um funcionamento puramente automático, [...] um tipo funcional, entorpecido e 'tranquilizado' de comportamento" (ARENDT, 2016, p. 400). Consoante um interlocutor nosso, "nem Hannah Arendt, para quem o mundo contemporâneo caracterizou-se pela perda das experiências, afetivas e existenciais, teria imaginado um mundo tão tecnológico de anulação dos indivíduos e de suas subjetividades" (TELES, 2018, p. 431). Ser livre para ir e vir e estar livre da fome não constituem pura e simplesmente o fundamento da liberdade política. De acordo com a autora que aqui acompanhamos, a essência da liberdade política emerge em sua grandeza apenas quando acontece a participação e a influente inserção dos humanos no debate público e nas decisões da cidade. Com a vitória do animal laborans, na dinâmica de algo que podemos interpretar como uma zoocracia, uma governamentalidade do mero viver, o que denominamos de cidadania é esvaziado de participação política, reduzido quando muito ao mecanismo da representação: atribuímos aos políticos profissionais os rumos da cidade, para que os indivíduos tenham energia e tempo suficientes para a corrida dos interesses privados. "Os elementos apáticos da sociedade burguesa, por mais que relutem em assumir as responsabilidades de cidadãos, mantêm intacta a sua personalidade, pelo menos porque ela lhes permite sobreviver na luta competitiva pela vida" (ARENDT, 1989, p. 363). A perspectiva nesse cenário não é das mais animadoras para se recuperar a dignidade da política: "é perfeitamente concebível que a era moderna - que teve início com um surto tão promissor e tão sem precedentes de atividade humana - venha a terminar na passividade mais mortal e estéril que a história jamais conheceu" (ARENDT, 2016, p. 400).

\section{O animal laborans centrifugado pela máquina antropológica}

Tendo o animal laborans saído vitorioso do processo histórico que denominamos de modernidade, será ele centrifugado pela máquina antropológica. Mas o homem animalizado que 
sairá dos tubos dessa máquina não será apenas um animal abandonado, será também um animal em cativeiro. Não estamos certamente nos referindo a animais de estimação que são muito bem tratados, muitas vezes melhor do que seres humanos - nem estamos defendendo que os animais não sejam bem tratados, nem que a relação não seja pessoal ou até que animais não tenham direitos. Estamos nos referindo à condição animal de sermos seres biológicos, devotados à satisfação de nossas necessidades e dos nossos instintos mais básicos. Tanto para Arendt quanto para Agamben, o animal é uma figura que antecede ao homem na escala biológica evolutiva, e embora possa ser gregário, carece de política. Atravessando a máquina antropológica, que seciona as entranhas, o produto será um homem comparado ao animal no que este pode ter de desamparado, de abandonado, de cativo. Sem compreender os traços específicos da relação entre o homem e o animal na modernidade, não se pode examinar a condição do ser humano e as relações atuais. Talvez "as aporias da filosofia de nosso tempo coincidam com as aporias desse corpo irredutivelmente teso e dividido entre animalidade e humanidade" (AGAMBEN, 2013, p. 27). Cabe ainda à filosofia que não receia se arriscar uma palavra diagnóstica esclarecedora, passo relevante para se buscar tratamento adequado e emancipação. No que concerne à máquina antropológica, é preciso "compreender o seu funcionamento, para poder, eventualmente, fazê-la parar" (AGAMBEN, 2013, p. 65).

O que costumamos denominar de ser humano é um ser histórico que permanece em constante tensão entre a humanidade que deseja garantir e a animalidade que pretende recusar. Se aproveitando de uma análise atenta do filósofo russo Alexander Kojève, Giorgio Agamben oferece no terceiro capítulo de $O$ aberto: o bomem e o animal uma definição do que compreende por máquina antropológica clássica.

\footnotetext{
$\mathrm{Na}$ leitura hegeliana de Kojève, o homem não é, de fato, uma espécie biologicamente definida nem uma substância dada de uma vez por todas; é, acima de tudo, um campo de tensões dialéticas sempre já talhado por cortes que nele separam toda vez - pelo menos virtualmente - a animalidade "antropófora" e a humanidade que nela se encarna. O homem existe historicamente apenas sob esta tensão: ele pode ser humano apenas na medida em que transcende e transforma o animal antropóforo que o sustenta, somente porque, por meio da ação negadora, é capaz de dominá-lo e, eventualmente, de destruir sua própria animalidade (AGAMBEN, 2013, p. 26).
}

Ocorre que ao lado da máquina antropológica clássica há uma outra que funciona em versão moderna, produzindo não o homem a partir do animal, mas o homem animalizado, ou melhor, uma espécie de animal que não parecer ser, a rigor, nem homem nem animal, mas um terceiro que parece estar mais próximo de uma vida nua, uma vida natural reconhecida enquanto tal mas não mais do que isso. Aliás, uma vida sem qualquer dignidade, sempre na iminência da exposição da morte. Máquina antropológica na variante moderna, portanto. Biopolítica, como se tornou evidente. "Os campos de concentração e de extermínio são um experimento deste gênero, uma tentativa extrema e monstruosa de decidir entre o humano e o inumano, que acabou por 
envolver em sua ruína a própria possibilidade de distinção" (2013, p. 43). Fora dos campos totalitários, nos campos das democracias que construímos aos trancos e barrancos, outras tentativas menos extremas e monstruosas chegam a resultados semelhantes. Nessa perspectiva, culminando as tensões metafísicas e políticas contidas nessa zona de indiferenciação entre a animalidade e a humanidade, temos o capítulo nono, com a descrição da máquina antropológica dos modernos. Vejamos como funciona portanto a segunda versão.

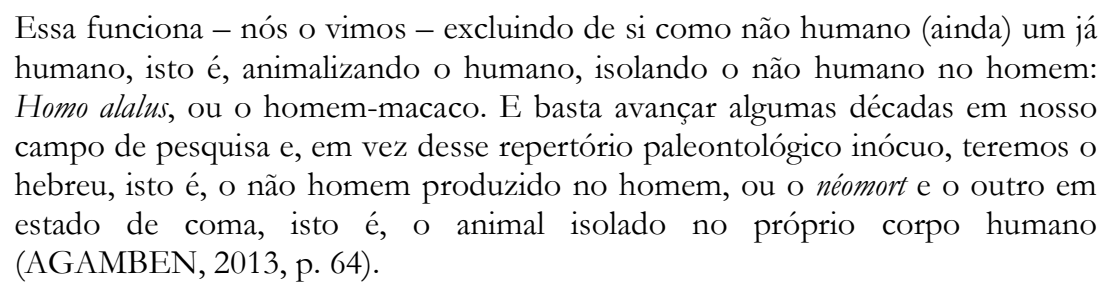

Segundo o filósofo italiano, os humanismos antigo e moderno buscam encontrar o missing link entre o humano e o animal. Com o avanço das ciências humanas do século dezenove, a máquina antropológica do humanismo moderno é alavancada e legitimada por meio do discurso científico. Determinadas concepções antropológicas impactam diretamente nas noções jurídicas, econômicas e políticas acerca do que é o ser humano. A eloquência da ciência moderna aparece como espaço fecundo de mobilização, manipulação e controle dos corpos. As diversas ciências do homem legislam e decidem o que é humano, e consequentemente, quais práticas, políticas e morais devem fixar a ordem pública. Tendo como ponto de apoio, contudo, uma zona de indiferença entre o homem e o animal, as máquinas antropológicas giram no vazio, como em um espaço de exceção, "e o verdadeiro humano que deve surgir é apenas o lugar de uma decisão incessantemente atualizada na qual a separação e sua rearticulação são sempre deslocalizadas e adiadas novamente" (AGAMBEN, 2013, p. 65). Como resultado, temos que "isso que deveria ser assim obtido não é semelhante nem a uma vida animal nem a uma vida humana, mas somente uma vida separada e excluída de si mesma - apenas uma vida nua". Claro está que o produto da máquina antropológica moderna adquire concretude no escravo, no estrangeiro, no miserável. Claro está que uma vida humana contemporânea assim compreendida que não pode não deixar de ser despolitizada.

\section{Considerações finais}

Em proporções e estilos diferentes, Arendt e Agamben compartilham do mesmo sentimento de nebulosa incerteza diante do contexto histórico que se desvela. O avanço da economia sobre a política conduz à apatia das populações e a redução de todas as dimensões da vida ao plano meramente metabólico ou à sobrevivência. Nas democracias contemporâneas em que procuramos nos mover, muito dedicadas às honrarias da tradição liberal, somos constantemente desafiados pela concentração no bem-estar individual e pelo abandono do espaço público, novamente confrontados pelo "perigo de confundir a felicidade pública e o bem-estar privado" 
(ARENDT, 2011, p. 173). A vitória do animal laborans e o giro da máquina antropológica potencializam a visão de liberdade compreendida como ausência de constrangimento por meio do qual o homem burguês pode dar livre curso aos seus negócios. O Estado apenas existe como um aparato racional-legal para defender os interesses particulares dos indivíduos identificados à condição de proprietários, sendo a segurança a meta política fundamental (cf. CORREIA, 2015, p. 154). A análise crítica dos autores que trazemos à colação detecta, via gestão da vida biológica e redução dos seres humanos às necessidades vitais, um acentuado processo de despolitização. Perante a apatia da sociedade de massas inundada de demagogia e a ascensão do nacionalpopulismo (cf. EATWELL; GOODWIN, 2020), o maior desafio das democracias em construção é criar poder político baseado no diálogo, na liberdade e na participação coletiva. Para tanto, é preciso que emerja nesse cenário não o burguês, mas o cidadão (cf. ARENDT, 2021, p. 524). E "para ser livre, o homem deve ter-se libertado das necessidades da vida" (ARENDT, 2014, p. 194), das necessidades e da excessiva preocupação com as mesmas necessidades, desprendendo-se, se possível for, das necessidades não necessárias. Quiçá uma luz meridiana que ilumine as filosofias do nosso tempo possibilite acreditar na liberdade como uma faculdade de superar o estado do animal laborans, interromper com o automatismo burocrático e biopolítico da máquina antropológica e com qualquer outra forma de governo que seja alicerçada no mero estar vivo.

Questiona-se a opulência do american way of life e a apatia das massas devotadas ao bem-estar privado, contudo, o cerne da teoria de Hannah Arendt é a confiança na liberdade política e a sua possibilidade de conduzir o homem na realização de milagres: é da própria natureza da ação humana surgir no mundo como uma improbabilidade infinita, e é "justamente esse infinitamente improvável que constitui de fato a verdadeira trama de tudo que denominamos real" (ARENDT, 2014, p. 218). Reconhecidas as diferenças conceituais e de tonalidade, notamos que alguma semelhança entre os autores que nos trouxeram até aqui acontece porque ambos conhecem as imensas dificuldades de uma democracia pautada na ativa participação dos cidadãos. Para além da ciranda do mundo jurídico-político de homines sacri e de um mundo no qual a vida nua é ao mesmo tempo o fundamento escondido da soberania e a forma de vida hoje dominante (cf. AGAMBEN, 1996, p. 15), há em Giorgio Agamben uma genuína apreensão com a liberdade humana e a sua contração.

Escrevemos estas páginas no decorrer de uma pandemia ${ }^{5}$. Durante o mesmo período, vimos o filósofo italiano publicar uma série de pequenos textos expressando todo o seu desconforto com a adoção de medidas sanitárias que restringiram as liberdades civis e humanas, embora não compactuemos com muitas das suas análises na medida em que não consideramos que a pandemia seja apenas um pretexto ideal (cf. NASCIMENTO, 2021). Seja como for, muitos dos

\footnotetext{
${ }^{5}$ Esse texto é também o resultado das conversações e das reflexões que tiveram lugar no desenvolvimento da disciplina Tópicos Especiais em Filosofia Política pelo Programa de Pós-Graduação em Filosofia da Universidade Federal do Espírito Santo, de junho a setembro de 2021, em formato remoto, sob a liderança dos professores Adriano Correia Silva e Daniel Arruda Nascimento.
} 
textos publicados têm como tema de fundo a perda da liberdade e o impacto que isso pode ter na política contemporânea. Com o regime de distanciamento social imposto em razão da disseminação do vírus Sars-Cov-2, os poderes soberanos teriam logrado resultados restritivos superiores a outros regimes tradicionalmente repressivos ou bélicos, convertendo o nosso mundo em um laboratório, impossibilitando a política e alargando o campo populacional de "uma massa rarefeita e fundada sobre uma proibição, mas, justo por isso, especialmente compacta e passiva" (AGAMBEN, 2020, p. 41). Se as relações humanas que tornam possível a política não existirem mais, não haverá mais política, cada homem cuidará da sua própria sobrevivência. "Depois que a política foi substituída pela economia, agora esta também, para poder governar, terá de ser integrada ao novo paradigma da biossegurança, a qual todas as demais exigências deverão ser sacrificadas" (AGAMBEN, 2020, p. 77). Ou seja, a política que se avizinha nesse registro, portanto, não seria mais política, pelo menos não aquela baseada em relações humanas, insubstituíveis inteiramente por aparatos tecnológicos. Segundo o filósofo italiano, não obstante, se as pessoas aceitaram as limitações as quais foram submetidas desde o início da pandemia do novo coronavírus, isto ocorreu não somente pelo medo da pandemia e pelos cuidados impostos pelas agências sanitárias, mas presumivelmente porque, mais ou menos inconscientemente, sabiam que o mundo em que haviam vivido até então não podia continuar (cf. AGAMBEN, 2020). O mundo que Hannah Arendt conheceu já não existiria mais.

Terminemos essas linhas com um intrigante texto de Agamben, muito recente. Ainda inconformado com as restrições impostas pelas autoridades sanitárias e pelos poderes dominantes em razão da pandemia, ele publica dois parágrafos com o título Homens e lêmingues, sugerindo a comparação. Se as noções de animal laborans e máquina antropológica haviam sido mobilizadas para alertar sobre a crise da política, a vida passiva e a vida biopolítica, a imagem dos pequenos roedores do bioma ártico será utilizada para fazer chacota de um suposto instinto de morte que atualmente nos acomete. O que interessa nesses pequenos animais é que se atiram nas águas de mares, lagos e rios em um aparente movimento de suicídio em grupo, não se sabe se por um estranho instinto migratório de sobrevivência ou por um indefectível instinto de morte. Escreve o filósofo italiano, não sem ironia: "eu creio que alguma coisa semelhante está hoje acontecendo em outra espécie de vivente, aquela que nós chamamos de homo sapiens". Esse é para a humanidade um movimento contraditório, porém: "os homens se encontram talvez pela primeira vez reduzidos à sua pura sobrevivência biológica, que, ao que parece, se revelam incapazes de aceitar” (AGAMBEN, 2021). Estaríamos em uma jornada suicida? Ou quer nosso autor acentuar o fato de sermos passivos como um rebanho? A imagem dos lêmingues, ou lemingos que soa melhor em português, já foi requentada algumas vezes por pensadores e artistas, sendo onipresente no continente europeu. Por aqui, há algum tempo atrás, era comum o uso da expressão Maria-vai-com-as-outras. Atualíssima, no entanto, é mesmo a imagem do gado .

\footnotetext{
${ }^{6}$ Não é à toa que a prova do Exame Nacional do Ensino Médio aplicado em 21 de novembro de 2021 traz questão com a música Admirável gado novo do cantor paraibano Zé Ramalho. A passividade social de um povo
} 


\section{REFERÊNCIAS BIBLIOGRÁFICAS}

AGAMBEN, G. Homo sacer: o poder soberano e a vida nua, tradução de Henrique Burigo, Belo Horizonte: Editora UFMG, 2002.

AGAMBEN, G. Mezzi senza fine: note sulla politica, Torino: Bollati Boringhieri, 1996.

AGAMBEN, G. O aberto: o homem e o animal, tradução de Pedro Mendes, Rio de Janeiro: Civilização Brasileira, 2013.

AGAMBEN, G. En qué punto estamos? La epidemia como política, traducciones de Artillería Inmanente, 2020. Disponível em <https://artilleriainmanente.noblogs.org/?p=1709>. Acesso em 31/08/2020.

AGAMBEN, G. Sul tempo che viene, Quodlibet, 23/11/2020. Disponível em <https://www. quodlibet.it/giorgio-agamben-sul-tempo-che-viene>. Acesso em 04/05/2021.

AGAMBEN, G. Uomini e lemmings, Quodlibet, 28/07/2021. Disponível em <https://www. quodlibet.it/giorgio-agamben-uomini-e-lemmings>. Acesso em 23/11/2021.

AGUIAR, O. A. Hannah Arendt e o direito I, Argumentos: Revista de Filosofia, ano 09, no 18, Fortaleza, jul./dez. 2017, pp. 87-94.

ALMEIDA, C. R. R. Do social à questão social: Hannah Arendt entre a Zoologia e a Teologia da compaixão. 2020. Tese (Doutorado em Filosofia) - Faculdade de Filosofia, Letras e Ciências Humanas, Universidade de São Paulo, São Paulo, 2020.

ARENDT, H. A condição humana, tradução de Roberto Raposo, revisão técnica e apresentação de Adriano Correia, Rio de Janeiro: Forense Universitária, 2016.

ARENDT, H. As origens do totalitarismo, tradução de Roberto Raposo, São Paulo: Companhia das Letras, 1989.

ARENDT, H. Eichmann em Jerusalém: um relato sobre a banalidade do mal, tradução de José Rubens Siqueira, São Paulo: Companhia das Letras, 1999.

ARENDT, H. Compreender: formação, exílio e totalitarismo (ensaios 1930 - 1954), tradução de Denise Bottmann, São Paulo/Belo Horizonte: Companhia da Letras/Editora UFMG, 2008.

ARENDT, H. A promessa da politica, organização e introdução de Jerome Kohn, tradução de Pedro Jorgensen, Rio de Janeiro: Difel, 2009.

ARENDT, H. Sobre a revolução, tradução de Denise Bottmann, São Paulo: Companhia da Letras, 2011.

ARENDT, H. Entre o passado e o futuro, tradução de Mauro W. Barbosa, São Paulo: Perspectiva, 2014.

ARENDT, H. Pensar sem corrimão: compreender 1953-1975, tradução de Beatriz Andreioulo, Rio de Janeiro: Bazar do Tempo, 2021.

massificado, marcado e feliz remete-nos à imagem do gado tão presente nos imensos pastos brasileiros. Informação disponível, por exemplo, em < bttps:// wmw1.folha.uol.com.br/educacao/2021/11/enem-tem-questoes-coma-musica-admiravel-gado-novo-e-indigenas.shtml>. Acesso em 23/11/2021. 
CORREIA, A. Hannah Arendt e a modernidade: politica, economia e a disputa por uma fronteira, Rio de Janeiro: Forense Universitária, 2014.

CORREIA, A. Quem é o animal laborans de Hannah Arendt? Revista de Filosofia Aurora, vol. 25, n 37, Curitiba, jul./dez. 2013, pp. 199-222.

CORREIA, A. Arendt sobre Hobbes como o verdadeiro filósofo da burguesia, Revista Interdisciplinar Interthesis, Florianópolis, vol. 12, nº 01, Jan-Jun. 2015, pp. 147-156.

EATWELL, R.; GOODWIN, M. Nacional-populismo: a revolta contra a democracia liberal, Rio de Janeiro: Record, 2020.

HAN, B.-C. Sociedade do Cansaço, tradução de Enio Paulo Giachini, Petrópolis: Vozes, 2015.

NASCIMENTO, D. A. Umbrais de Giorgio Agamben: para onde nos conduz o homo sacer? São Paulo: LiberArs, 2014.

NASCIMENTO, D. A. Antropogênese e filosofia indígena: o homem e o animal, Griot: Revista de Filosofia, vol. 21, no 02, Amargosa, junho 2021, pp. 405-416.

NASCIMENTO, D. A. O filósofo e a pandemia um ano depois: entre uma epidemia inventada e a controversa defesa da vida, (Des)troços: Revista de Pensamento Radical, vol. 02, nº 01, Belo Horizonte, jan./jun. 2021, pp. 251-265.

REALE, G.; ANTISERI, D. Filosofia: Antiguidade e Idade Média, vol. I, São Paulo: Paulus, 2005.

TELES, E. Governamentalidade algorítmica e as subjetivações rarefeitas, Revista Kriterion, no ${ }^{\circ}$ 140, Belo Horizonte, Ago./2018, pp. 429-448. 